\title{
The detection of verocytotoxins in bacterial cultures from human diarrhoeal samples with monoclonal antibody-based ELISAs
}

\author{
H. J. BALL, D. FINLAY, A. ZAFAR* and T. WILSON* \\ Veterinary Sciences Division, Stoney Road, Stormont, Belfast BT4 $3 S D$ and *Northern Ireland Public Health \\ Laboratory, Belfast City Hospital, Lisburn Road, Belfast BT9 7AB, Northern Ireland
}

\begin{abstract}
Bacterial cultures from 1801 human diarrhoeal faecal specimens were examined for verocytotoxins I and II by monoclonal antibody-based sandwich ELISAs. Of the 68 ELISA-positive cultures selected from initial screening, 32 were positive by ELISA on repeat or from freshly grown cultures. ELISA-positive pure cultures were obtained from 13 of these, of which seven were confirmed as verocytotoxin positive by cytotoxicity assay. These seven strains were typed as 026 (5) and 0146 (2). The six false positive results were from isolates of Enterobacter sp. (1), Citrobacter freundii (1) and Escherichia coli (4), one each of types O1, O18ac and 098 and an untypable strain. Despite the occurrence of false positive reactions, sandwich ELISA was a useful method for the rapid screening of samples, and detected verocytotoxin-positive $E$. coli strains, other than 0157, from patients with clinical conditions in which they could be implicated.
\end{abstract}

\section{Introduction}

The enterohaemorrhagic Escherichia coli (EHEC) are characterised by the production of cytotoxins known as verocytotoxins (VTs) or Shiga-like toxins [1]. These toxins are regarded as important virulence factors that contribute to EHEC-associated human diseases such as haemorrhagic colitis and haemolytic uraemic syndrome $[2,3]$.

Most human disease attributed to EHEC has been caused by E. coli serotype O157, although other Oserotypes have been implicated in haemorrhagic enteritis [4] and haemolytic uraemic syndrome [5]. This has led to the development of selective diagnostic methods for the detection of 0157 [6-10]. Because of the predominant use of these selective methods for screening human specimens, clinically significant $E$. coli strains other than $\mathrm{O} 157$ may not be detected.

Various sandwich ELISAs have been used for the detection of verocytotoxins of types I and II (VTI and VTII). These have used various combinations of monoclonal antibodies (MAbs), polyclonal antibodies and the natural glycolipid VT cell receptor [11-15]. The ELISAs in the present study had MAb on both sides of the sandwich and were developed originally to screen cultures from cattle faeces for VTI and VTII [16]. In the present investigation, the assays were used to screen human enteric isolates.

Received 3 Aug. 1995; revised version accepted 5 Oct. 1995.

Corresponding author: Dr H. J. Ball.

\section{Materials and methods}

Test samples

Faecal samples from patients with diarrhoea submitted for diagnosis to the Northern Ireland Public Health Laboratory were each processed as follows. A colony sweep from an overnight blood agar culture of faeces incubated at $37^{\circ} \mathrm{C}$ was collected into $1 \mathrm{ml}$ of $0.1 \mathrm{M}$ PBS and stored at $-20^{\circ} \mathrm{C}$ before testing. A volume of prethawed suspension was mixed with an equal volume of polymyxin solution in PBS, to give a final polymyxin concentration of $2 \mathrm{~g} / \mathrm{L}$. This was incubated at $37^{\circ} \mathrm{C}$ for $30 \mathrm{~min}$ and left at $4^{\circ} \mathrm{C}$ overnight to allow the majority of the particulate cellular material to settle. The supernate was removed carefully from the sediment and mixed with an equal volume of PTN ( $0.01 \mathrm{M}$ PBS with Tween $800.04 \%$ and additional sodium chloride $2 \%)$ to provide the test sample for the ELISAs.

Colony sweeps from subcultured samples of the original mixed cultures, or from cultures purified from single colony subculture, were collected directly into PBS containing polymyxin $2 \mathrm{~g} / \mathrm{L}$ before being processed as described above.

\section{Sandwich ELISAS}

The processed cell extracts were examined for VTI and VTII (non-variant) by MAb-based sandwich ELISAs with VTI-specific MAb 13C4 [17] and VTII-specific MAbs 11E10 and 11F11 [18] respectively. The hybridoma cell lines were obtained from the American Type Culture Collection (Rockville, MD, USA) and 
used as described previously [16]; MAb 13C4 could be used on both sides of an ELISA, but the detection of VTII (non-variant) required capture and development of the assay by different MAbs. MAbs were purified from ascites collected from $\mathrm{BALB} / \mathrm{c}$ mice inoculated with the corresponding hybridoma cell line [19] by the caprylic acid method [20]. Some of the purified 13C4 and 11E10 MAbs were also biotinylated [21].

Microtitration wells for sandwich ELISAs were coated with capture MAb (13C4 for VTI and $11 \mathrm{~F} 11$ for VTII) in $0.05 \mathrm{M}$ carbonate buffer, $\mathrm{pH} 9.5$, at $4^{\circ} \mathrm{C}$ overnight. The wells were washed after each incubation stage with five changes of $0.01 \mathrm{M}$ PBS, $\mathrm{pH} 7.2$, containing Tween $200.05 \%$, and all subsequent incubations were at $37^{\circ} \mathrm{C}$. After $1-\mathrm{h}$ incubation stages of duplicate test samples, biotinylated MAb (13C4 for VTI and 11E10 for VTII) and streptavidin peroxidase (Sigma) substrate were added. The latter consisted of $100 \mu 1$ of a solution of $3,3^{\prime}, 5,5^{\prime}$-tetramethyl benzidine (Sigma) $10 \mathrm{~g} / \mathrm{L}$ of dimethyl sulphoxide and $10 \mu \mathrm{l}$ of hydrogen peroxide per $10 \mathrm{ml}$ of $0.1 \mathrm{M}$ citrate phosphate buffer, $\mathrm{pH}$ 5.0. All reagents and test samples were used in $100 \mu \mathrm{l}$ volumes except for the final addition of $50 \mu \mathrm{l}$ of $2.5 \mathrm{M}$ sulphuric acid to stop the substrate reaction after incubation for $10-20 \mathrm{~min}$.

VTI and VTII positive E. coli strains were used as positive controls and a negative control consisted of PTN in place of the test sample. Absorbance was measured at $450 \mathrm{~nm}$ with an ELISA plate reader (Titertek, Multiskan). All test readings greater than four times the negative control reading were taken as positive and readings between three and four times the negative control were regarded as borderline. The absorption readings of the negative controls were typically $c$. 0.05 , those of the borderline readings between 0.150 and 0.200 and those of the positive readings $>0.200$, but variations occurred depending on the length of substrate incubation.

Sample volumes from the majority of cultures that were VT-positive or borderline from the first screening were re-processed with polymyxin and re-tested. Also, they were freshly cultured on blood agar plates that were harvested and processed after overnight incubation. A positive reaction in either repeat test was taken as confirmation of the presence of verocytotoxin; such samples were re-cultured and up to 20 single colonies were picked off and cultured for individual testing. Each of these series of assays was performed once, but duplicates of each sample were used on each occasion.

\section{Cytotoxicity}

Extracts from all purified cultures with ELISA activity were tested for toxicity against Vero cells as described previously [16].

\section{Serotyping}

Verocytotoxin-positive purified strains of $E$. coli were $\mathrm{O}$-somatic antigen serotyped by standard agglutination procedures [22] with 45 rabbit antisera as described previously [16]. Strains that failed to type with these sera were tested by the Laboratory of Enteric Pathogens, Central Public Health Laboratory, Colindale Avenue, London.

\section{Results}

The sandwich ELISA VT results are summarised in Table $1 ; 68(3.8 \%)$ of the 1801 samples tested were VT-positive from the initial screening. Of these, 36 were borderline, but only 10 remained borderline on repeat testing of the original or of a fresh culture; one culture, which was still borderline positive, was purified from these. Twenty-two of the remaining 32 cultures remained positive on repeat testing and ELISA-positive purified cultures, grown from single colonies, were obtained from 12 of these.

Of the 13 purified strains, only seven were confirmed as VT-positive by cytotoxicity tests; these were five strains of serotype 026 , three of which were from separate samples from the same patient, and two strains of serotype O146. These seven purified strains all gave ELISA readings at least 10 times those of the negative controls. The ELISA-positive/cytotoxicitynegative strains consisted of one strain each of Enterobacter sp., Citrobacter freundii and $E$. coli strains of types O1, O18ac, O98 and an untypable strain. E. coli $\mathrm{O} 1$ and O18ac demonstrated ELISA readings as high as the ELISA positive results confirmed by cytotoxicity, E. coli $\mathrm{O} 98$ and $C$. freundii gave ELISA readings between four and five times

Table 1. Verocytotoxin sandwich ELISA results from blood agar cultures from human diarrhoeal specimens

\begin{tabular}{|c|c|c|c|}
\hline $\begin{array}{l}\text { Number of } \\
\text { samples } \\
\text { tested }\end{array}$ & $\begin{array}{l}\text { Number (\%) } \\
\text { of samples } \\
\text { ELISA positive } \\
\text { by initial } \\
\text { screening }\end{array}$ & $\begin{array}{l}\text { Number }(\%) \\
\text { of samples } \\
\text { positive on } \\
\text { repeat or in } \\
\text { freshly grown culture }\end{array}$ & $\begin{array}{c}\text { Number }(\%) \\
\text { of ELISA } \\
\text { positive pure } \\
\text { cultures from } \\
\text { single colonies }\end{array}$ \\
\hline 1801 & $68(3.8)$ & $32(1.8)$ & $13(0.7)$ \\
\hline
\end{tabular}


those of the negative controls and the untypable $E$. coli strain and the Enterobacter sp. gave borderline ELISA readings.

Six of the seven purified strains that were ELISApositive and confirmed as verocytotoxin positive by cytotoxicity were positive with the VTI ELISA only; only one of the $\mathrm{O} 26$ strains gave positive results with both VTI and VTII ELISAs. The ELISA false positive $C$. freundii and the $E$. coli $\mathrm{O} 1$ and untypable strains were VTI ELISA-positive, the $E$. coli O18ac was VTII ELISA-positive, and the remaining Enterobacter sp. and E. coli 098 were both VTI and VTII ELISApositive.

All the faecal samples submitted to the Public Health Laboratory were examined for common bacterial and parasitic causes of diarrhoea. The only significant pathogens detected from the cultures from which ELISA-positive pure cultures were obtained were from those which contained VT false positive strains. Clostridium difficile toxin, Blastocystis hominis cysts and a Campylobacter sp. were identified in cultures that contained the ELISA-positive $C$. freundii, $E$. coli $\mathrm{O} 1$ and $E$. coli untypable strains, respectively.

Clinical details were obtained retrospectively on the five patients from whom the seven confirmed VTpositive strains were isolated, and are summarised in Table 2. None of these patients exhibited features of haemorrhagic enteritis (blood in stools) or haemolytic uraemic syndrome (renal failure), but all had diarrhoea, with or without vomiting, four of them for prolonged periods ( 2 weeks -6 months).

\section{Discussion}

E. coli strains producing VT toxins were confirmed in seven $(0.4 \%)$ of the 1801 cultures tested. These were associated with cases of diarrhoea from which no other suspect causative organism was isolated. Six of the purified strains that demonstrated ELISA-positive activity were not confirmed as VT producers by the cytotoxicity assay; four of these reactors gave low ELISA readings, just above or below the cut-off point used, but two, typed as $\mathrm{O} 1$ and $018 \mathrm{ac}$, gave ELISA readings as high as the VT strains confirmed by cytotoxicity. The number of false positive results could be reduced by raising the ELISA cut-off point to five times that of the negative control, but the high ELISA readings produced by the $\mathrm{O} 1$ and $018 \mathrm{ac}$ strains demonstrated significant non-specificity in both ELISAs. These results confirm the findings of previous work with these ELISAs in a survey of faecal $E$. coli isolates from cattle [16].

The VT survey of cattle faecal samples found equal numbers of VT-positive activity in samples from normal $(27 \%)$ and diarrhoeal $(21 \%)$ faeces in primary mixed colony sweeps. Cultures were not collected from normal faeces in this study, but positive ELISA results have been recorded in two (4\%) of 51 healthy control samples in another study [23]. Since it can be assumed that all VT strains that were present at levels within the range of sensitivity of the ELISAs were detected, the low number of ELISA reactions demonstrated by the initial screening also indicates a low incidence of VT strains in human faeces.

In comparison with the cytotoxicity test, the ELISAs provided a simple method of screening the large number of samples examined, although the cytotoxicity test appears to be necessary to confirm any ELISA-positive reactions. The 32 cultures that were ELISA-positive on repeat testing are probably more representative of the number of true ELISA-positive strains than the 68 detected by the initial screening. The fact that only 13 ELISA-positive strains were purified from these 32 cultures is probably indicative of the low incidence of these strains in the mixed cultures. Karmali et al. [24] demonstrated that VTpositive strains present in as few as $1.5 \%$ of a mixed population are detectable by cytotoxicity tests. Such a low incidence is unlikely to have been purified by the procedure used in the present study. The clinical significance of such a low incidence of VT-positive strains is uncertain but the numbers of $E$. coli 0157 have been found to fall very quickly after the onset of diarrhoea, and this organism is often difficult to isolate after the first 6 days of illness [25].

Because of the false positive results obtained with six of the purified cultures, it is difficult to evaluate the clinical significance of the ELISA-positive mixed cultures from which ELISA-positive pure cultures were not obtained. Some significance can be attributed to the confirmed VT-positive strains purified, since

Table 2. Clinical details of patients with confirmed verocytotoxin-positive $E$. coli

\begin{tabular}{|c|c|c|c|c|c|c|c|c|}
\hline $\begin{array}{l}E . \text { coli } \\
\text { serotype }\end{array}$ & Source & $\begin{array}{c}\text { Age } \\
\text { (years) }\end{array}$ & $\begin{array}{c}\text { Sex } \\
(\mathrm{M} / \mathrm{F})\end{array}$ & Diarrhoea & Vomiting & $\begin{array}{l}\text { Blood in } \\
\text { stools }\end{array}$ & $\begin{array}{l}\text { Renal } \\
\text { failure }\end{array}$ & $\begin{array}{c}\text { Duration of } \\
\text { diarrhoea }\end{array}$ \\
\hline $\mathrm{O} 26$ & Hospital & 77 & $\mathbf{M}$ & + & + & - & - & 5 weeks \\
\hline 0146 & Hospital & 93 & $\mathrm{~F}$ & + & + & - & - & 2 days \\
\hline 0146 & Hospital (opd) & 26 & $\mathbf{F}$ & + & - & - & - & 6 months \\
\hline O26 & GP & 1.3 & $\mathrm{~F}$ & + & - & - & - & 2 weeks \\
\hline 026 & GP & 2.3 & $\mathrm{~F}$ & + & + & - & - & 5 weeks \\
\hline
\end{tabular}

opd, out-patients department; GP, general practitioner. 
VT-producing strains of both $\mathrm{O} 26$ and $\mathrm{O} 146$ serotypes have been associated previously with human diarrhoea $[2,26]$. Another study expressed some doubt as to the clinical importance of two $\mathrm{O} 146$ strains that were isolated, neither of which possessed the EHEC plasmid or the ability to cause attaching and effacing lesions, factors that are thought to contribute to the virulence of VT-producing strains [27].

A reduction in the sensitivity of both ELISAs has been observed after freezing and thawing of cultures (personal observation). It is possible that this effect contributed to the activity lost from the re-processed original samples that had been positive from the first ELISA screening. A more efficient approach for the detection of VT activity might be to utilise the more sensitive cytotoxicity assays for re-testing mixed culture samples that had been screened initially by the ELISAs. The final identification of VT-producing strains by purification from positive mixed cultures is a laborious task with no guarantee of success.

The number of human isolates of E. coli 0157 in Northern Ireland has been very small (two in 1993 and three in 1994 [28]). The significant association of O157 with haemorrhagic enteritis and haemolytic uraemic syndrome has stimulated the development of selective methods for the isolation of 0157 . Although VT-producing strains other than 0157 have been isolated from haemolytic uraemic syndrome in Britain $[23,29]$, the specific testing for O157 in diagnostic laboratories has probably meant that other VT strains of clinical significance may have been overlooked. The ELISAs utilised in the present study provide a rapid screening method for the initial detection of VTpositive strains which would include 0157 .

We gratefully acknowledge the technical assistance of staff of the Bacteriology Departments at both the Veterinary Science Division and the Northern Ireland Public Health Laboratory.

\section{References}

1. Levine MM. Escherichia coli that causes diarrhea: enterotoxigenic, enteropathogenic, enteroinvasive, enterohaemorrhagic and enteroadherent. $J$ Infect Dis 1987; 155: 377-389.

2. Karmali MA. Infection by verocytotoxin-producing Escherichia coli. Clin Microbiol Rev 1989; 2: 15-38.

3. O'Brien, AD, Tesh VL, Donohue-Rolfe A et al. Shiga toxin: biochemistry, genetics, mode of action, and role in pathogenesis. In: Samsonetti PJ (ed) Pathogenesis of Shigellosis (Curr Top Microbiol Immunol 180) Berlin, Springer-Verlag. 1992: 65-94.

4. Bopp CA, Greene KD, Downes FP, Sowers EG, Wells JG, Wachsmuth IK. Unusual verotoxin-producing Escherichia coli associated with hemorrhagic colitis. J Clin Microbiol 1987; 25: 1486-1489.

5. Tarr PI. Escherichia coli O157:H7: Overview of clinical and epidemiological issues. J Food Prot 1994; 57: 632-636.

6. March SB, Ratnam S. Sorbitol-MacConkey medium for the detection of Escherichia coli 0157:H7 associated with hemorrhagic colitis. J Clin Microbiol 1986; 23: 869-872.

7. Thompson JS, Hodge DS, Borczyk AA. Rapid biochemical test to identify verocytotoxin-positive strains of Escherichia coli serotype O157. J Clin Microbiol 1990; 28: 2165-2168.

8. Chapman PA, Siddons CA, Zadik PM, Jewes L. An improved selective medium for the isolation of Escherichia coli O157. $J$ Med Microbiol 1991; 35: 107-110.

9. Zadik PM, Chapman PA, Siddons CA. Use of tellurite for the selection of verocytotoxigenic Escherichia coli O157. J Med Microbiol 1993; 39: 155-158.

10. Chapman PA, Wright DJ, Siddons CA. A comparison of immunomagnetic separation and direct culture for the isolation of verocytotoxin-producing Escherichia coli $\mathrm{O} 157$ from bovine faeces. J Med Microbiol 1994; 40: 424 427.

11. Downes FP, Green JH, Green K, Strockbine N, Wells JG, Wachsmuth IK. Development and evaluation of enzyme-linked immunosorbent assays for detection of Shiga-like toxin I and Shiga-like toxin II. J Clin Microbiol 1989; 27: 1292-1297.

12. Ashkenazi S, Cleary TG. Rapid method to detect Shiga toxin and Shiga-like toxin I based on binding to globotriosyl ceramide $\left(\mathrm{GB}_{3}\right)$, their natural receptor. J Clin Microbiol 1989; 27: 11451150 .

13. Basta M, Karmali M, Lingwood C. Sensitive receptor-specific enzyme-linked immunosorbent assay for Escherichia coli verocytotoxin. J Clin Microbiol 1989; 27: 1617-1622.

14. Acheson DWK, Keusch GT, Lightowlers M, Donohue-Rolfe A. Enzyme-linked immunosorbent assay for Shiga toxin and Shigalike toxin II using $\mathrm{P}_{1}$ glycoprotein from hydatid cysts. $J$ Infect Dis 1990; 161: 134-137.

15. Law D, Hamour AA, Acheson DWK, Panigrahi H, Ganguli LA, Denning DW. Diagnosis of infections with Shiga-like toxinproducing Escherichia coli by use of enzyme-linked immunosorbent assays for Shiga-like toxins on cultured stool samples. J Med Microbiol 1994; 40: 241-245.

16. Ball HJ, Finlay D, Burns L, Mackie DP. Application of monoclonal antibody-based sandwich ELISAs to detect verotoxins in cattle faeces. Res Vet Sci 1994; 57: 225-232.

17. Strockbine NA, Marques LRM, Holmes RK, O'Brien AD. Characterisation of monoclonal antibodies against Shiga-like toxin from Escherichia coli. Infect Immun 1985; 50: 695-700.

18. Perera LP, Marques LRM, O'Brien AD. Isolation and characterization of monoclonal antibodies to Shiga-like toxin II of enterohemorrhagic Escherichia coli and use of the monoclonal antibodies in a colony enzyme-linked immunosorbent assay. $J$ Clin Microbiol 1988; 26: 2127-2131.

19. Mueller UW, Hawes CS, Jones WR. Monoclonal antibody production by hybridoma growth in Freund's adjuvant primed mice. J Immunol Methods 1986; 87: 193-196.

20. McKinney MM, Parkinson A. A simple, non-chromatographic procedure to purify immunoglobulins from serum and ascites fluid. J Immunol Methods 1987; 96: 271-278.

21. Hofmann K, Titus G, Montibeller JA, Finn FM. Avidin binding of carboxyl-substituted biotin and analogues. Biochemistry 1982; 21: $978-984$.

22. Ørskov F, Ørskov I. Serotyping of Escherichia coli. In: Bergan $\mathrm{T}$ (ed) Methods in microbiology, vol 14. London, Academic Press. 1984: 43-112.

23. Kleanthous H, Smith HR, Scotland SM et al. Haemolytic uraemic syndromes in the British Isles, 1985-88: association with verocytotoxin-producing Escherichia coli. Part 2: microbiological aspects. Arch Dis Child 1990; 65: 722-727.

24. Karmali MA, Petric M, Lim C, Cheung R, Arbus GS. Sensitive method for detecting low numbers of verotoxin-producing Escherichia coli in mixed cultures by use of colony sweeps and polymyxin extraction of verotoxin. $J$ Clin Microbiol 1985 ; 22: 614-619.

25. Tarr PI, Neill MA, Clausen CR, Watkins SL, Christie DL, Hickman RO. Escherichia coli $\mathrm{O} 157: \mathrm{H} 7$ and the hemolytic uremic syndrome: importance of early cultures in establishing the etiology. $J$ Infect Dis 1990; 162: 553-556.

26. Scotland SM, Willshaw GA, Smith HR, Rowe B. Properties of strains of Escherichia coli $\mathrm{O} 26: \mathrm{H} 11$ in relation to their enteropathogenic or enterohemorrhagic classification. $J$ Infect Dis 1990; 162: 1069-1074.

27. Barrett TJ, Kaper JB, Jerse AE, Wachsmuth IK. Virulence factors in Shiga-like toxin-producing Escherichia coli isolated from humans and cattle. $J$ Infect Dis 1992; 165: 979-980.

28. Communicable Diseases Report, Northern Ireland Mitchel E (ed). 1995; January: 1.

29. Scotland SM, Rowe B, Smith HR, Willshaw GA, Gross RJ. Vero cytotoxin-producing strains of Escherichia coli from children with haemolytic uraemic syndrome and their detection by specific DNA probes. J Med Microbiol 1988; 25: 237-243. 